\title{
INVESTIGATION OF THE EFFECT OF DIAMOND POWDER ON THE THERMAL PROPERTIES OF OCTADECANE USING DIFFERENTIAL SCANNING CALORIMETRY
}

\author{
Wojciech Godlewski, Mateusz Sierakowski \\ Roman Domański, Jakub Kapuściński \\ Eukasiewicz Research Network - Institute of Aviation \\ Krakowska Av. 110/114, 02-256 Warsaw \\ e-mail:wojtgod@wp.pl,m.sierako@gmail.com \\ roman.domanski@ilot.edu.pl,jakub.kapuscinski@ilot.edu.pl \\ Tomasz Wiśniewski, Michał Kubiś \\ Warsaw University of Technology \\ Institute of Heat Engineering \\ Nowowiejska Street 21/25, 00-665 Warsaw \\ e-mail: tomasz.wisniewski@itc.pw.edu.pl,michal.kubis@itc.pw.edu.pl
}

\begin{abstract}
The purpose of this work was to examine the effect of diamond powder on the thermal properties of phase change materials on the example of octadecane. The experiment involved mixing of diamond powder with a specific granulation with the aforementioned representative of the alkanes group. Two different grain sizes were used: 50 and 250 micrometres. The change of specific heat, latent heat of phase change and degree of supercoiling in newly formed mixtures was compared to the pure forms of the phase-change materials used. Initial mixing with a glass-stirring rod showed strong stratification for each granulation due to the low viscosity of the mixture and too large differences between component densities. It was decided to add amorphous silicon dioxide to the mixtures, which increases density of the mixture. The optimal percentage of amorphous silicon dioxide was estimated experimentally. Measurements of thermal parameters were carried out using DSC technology. The results of the tests of specific heat and latent phase transition heat showed that with the increasing content of diamond, the specific heat of the mixture decreases almost twice, and the latent heat can decrease by up to three times. The effect of diamond powder on reducing the degree of supercoiling of the mixture was also observed. An important observation was that the mixture with higher granulation of diamond powder had greater tendency for sedimentation. This method could be used to increase thermal conductivity and diffusivity of phase change materials and make them viable for use in systems that require cooling at high rate or temperature stabilization, such as control systems in electronic vehicles or aviation industry and at the same time decrease the degree of supercoiling which could increase the efficiency of system.
\end{abstract}

Keywords: phase change materials, PCM, diamond powder, thermal conductivity, thermal diffusivity

\section{Introduction}

Phase change materials are a part of thermal energy storage technology [1]. Energy is stored in the form of latent heat of phase change during melting or freezing. In comparison to conventional latent heat storages such as water or soil they can store as much as ten times more energy per unit of volume [2], therefore they could be used in systems with space and mass limitations such as electronic devices. These materials however, have serious drawback, which is low thermal conductivity and diffusivity, therefore they are unable to store or release energy at a high rate [3]. Due to this fact, their application is limited to systems that do not require fast cooling or heating. To resolve this problem, it was decided to investigate the influence of highly conductive diamond powder on these thermal properties of PCM's [4]. Mixtures were prepared with use of octadecane 
and two granulations of diamond -50 and $250 \mu \mathrm{m}$. During preparation mixtures, those shown high tendency of stratification. To resolve this, structure was enhanced with amorphous silicon dioxide. The mass of additive was determined experimentally. Furthermore, the change of heat capacity and latent heat were measured with use of Differential Scanning Calorimetry. Additionally, supercoiling effect in newly formed composites was investigated.

\section{Differential Scanning Calorimetry method and the experimental stand}

Differential Scanning Calorimetry is an instrumental analytical method, which consists of recording the difference in the flow of heat flux between the test substance and the environment (heating system) and the reference substance and the environment (heating system) as a function of temperature. As a result, the DSC curve, which represents the amount of heat exchanged by the sample with the environment per unit of time, is obtained. For this work, Perkin Elmer Differential Scanning Calorimeter DSC-7 with power compensation method and the constant heating rate was used. Calorimetric measurements are strongly connected with issues of heat and mass transfer. To study the methods of measuring specific heat, it is necessary to first define the specific heat [5]:

$$
c=\frac{d q}{d T} \text {. }
$$

According to definition of specific heat $c_{p}$ the quantity can be expressed as

$$
\Delta H=H_{f}-H_{i}=m \int_{T_{i}}^{T_{f}} C_{p}(T) d T=m * C_{p a}\left(T_{f}-T_{i}\right),
$$

where change of enthalpy $\Delta H$ of the sample of mass $m$ in temperature range between $T_{i}$ and $T_{f}$ is defined by the amount of heat delivered into sample causing the change of temperature in this range. Specific heat $c_{p a}$ obtained from this relation is an average value of specific heat in the range between $T_{i}$ and $T_{f}$. Latent heat of phase change can be defined as:

$$
\begin{gathered}
\Delta H=H_{f}-H_{i}=m\left[\int_{T_{i}}^{T_{m}} c_{p s}(T) d T+\Delta h_{t}+\int_{T_{m}}^{T_{f}} c_{p l}(T) d T\right], \\
\Delta H=H_{f}-H_{i}=m\left[C_{p s}(T) d T+\Delta h_{t}+C_{p l}(T) d T\right] .
\end{gathered}
$$
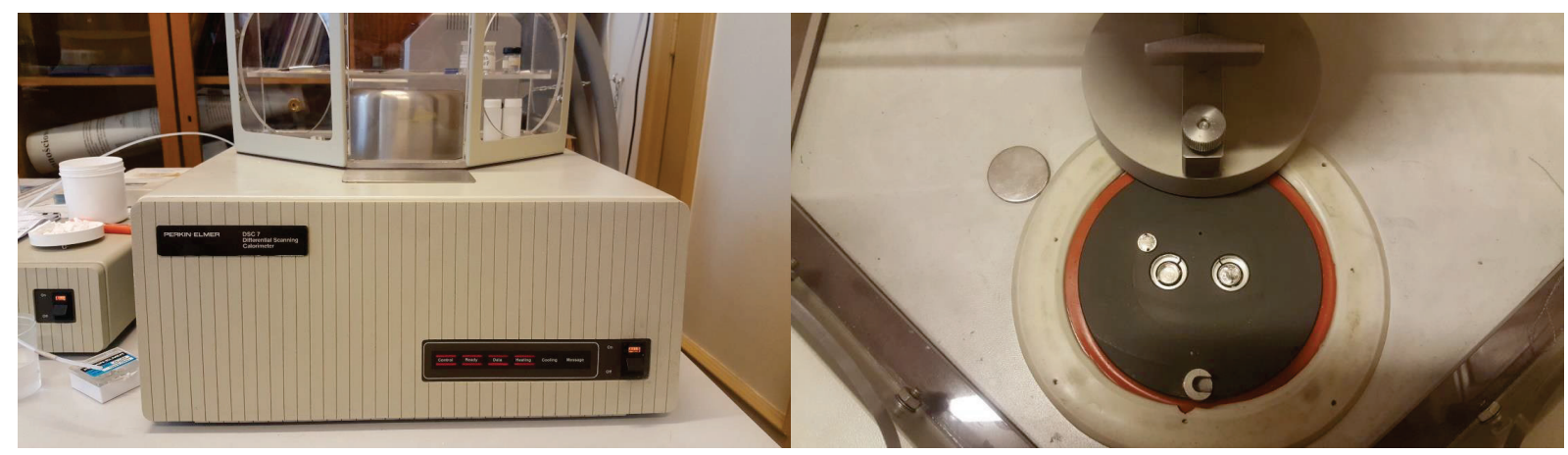

Fig. 1. Perkin Elmer Differential Scanning Calorimeter DSC-7......Fig. 2. DSC apparatus, inside of measuring cell

To measure properties of samples, the DSC was controlled with programme via Perkin Elmer TAC 7/3 Instrument Controller. Chosen settings were as follows - initial temperature: $5^{\circ} \mathrm{C}$, time of isotherm: 3 minutes, purge gas flow: $20 \mathrm{ml} / \mathrm{min}$, heating/cooling rate: $2 \mathrm{~K} / \mathrm{min}$, final temperature: $40^{\circ} \mathrm{C}$. The low initial temperature ensured a larger range of tests. According to the manufacturer, the melting temperature of octadecane is between $26-29^{\circ} \mathrm{C}$. The initial temperature was maintained for 3 minutes for stabilization. Inert gas, in this case argon, was used to stabilize measurement and assure the same conditions for every measurement. The lower heating rate provided higher accuracy of measurement. Lower measurement rate resulted in higher accuracy. Ministat 125 Compact cooling bath circulation thermostat provided further stabilisation of the process. 


\section{Preparation of samples}

It was decided to melt the sample directly in the glass cylinder in which mixing would be done to prevent the loss of the material while pouring it from one container to the other. To eliminate stratification phenomenon amorphous silicon dioxide was added to samples as a mass fraction. This material is widely used in science and industry as an electrical insulator, ingredient in food, pharmaceutics, and structural materials. Because of its high value of interstitial surface area of the voids and pores (specific surface area), reaching $380 \mathrm{~m}^{2} / \mathrm{g}$ it has very good thixotropic properties that allow creating a microstructure across the mixture that connects to the constituents making more homogeneous and viscous mixture. Because of its good availability and popularity, it was chosen as viscosity enhancer in the mixture. The samples were prepared starting from $0.25 \%$ mass fraction. Other samples were prepared by adding $0.25 \%$ of mass fraction of whole sample.

\section{Results of the experimental work}

During experiment, eight mixtures were tested: pure octadecane, octadecane with $4 \%$ of amorphous silicon dioxide, octadecane with 4\% of amorphous silicon dioxide and 10, 30 and 50\% mass fraction of $50 \mu \mathrm{m}$ diamond, octadecane with $4 \%$ of amorphous silicon dioxide and 10,30 and $50 \%$ mass fraction of $250 \mu \mathrm{m}$ diamond. Latent heat was calculated with use of software. To determine the dependence of the specific heat of the sample from the temperature the heating power, mass of the sample and the heating rate were used:

$$
C p=\frac{\Delta H}{\mathrm{~m} * \mathrm{dT} / \mathrm{dt}},
$$

where:

$C p \quad$ - heat capacity $[\mathrm{J} / \mathrm{g} / \mathrm{K}]$,

$\Delta H \quad$ - difference in heating power [ $\mathrm{mW}]$,

$\mathrm{m} \quad-$ mass of sample [mg],

$d T / d t$ - heating rate $[\mathrm{K} / \mathrm{min}]$.

\section{Measurement of specific heat}

Specific heat was calculated using DSC software. This was achieved by examining empty holder and then holder with the sample. The difference in heat flux between them provided $\Delta H$ used in the formula (5).

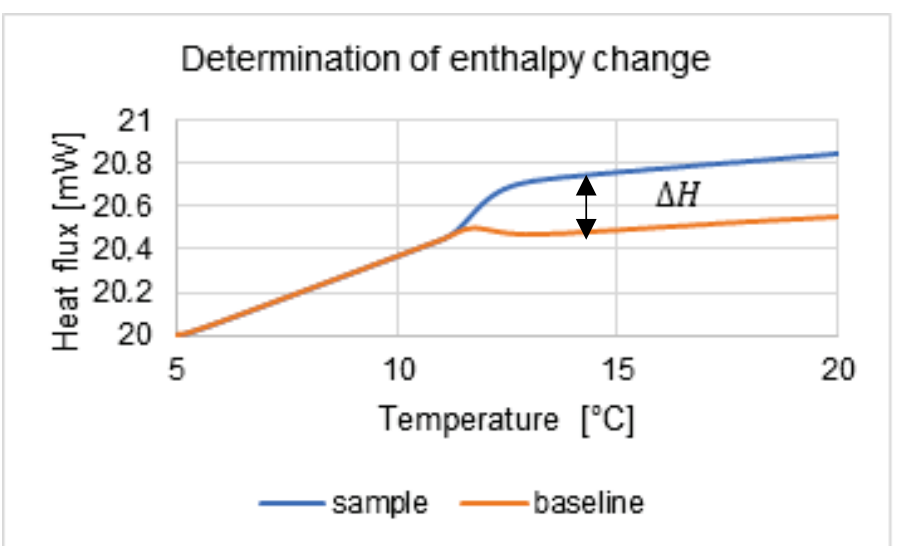

Fig. 3. Graphical representation of latent heat value

To compare the specific heat values of $\mathrm{PCM}, \mathrm{SiO}_{2}$ and diamond of different mass content and granulation mixtures with pure octadecane and octadecane mixed with $\mathrm{SiO}_{2}$, they were presented on 
a common $c_{p}(T)$ diagram Fig. 4 in the temperature range 30-40 degrees Celsius where the results were most stable.

Average values of $c_{p}$ for 3 samples of each mixture
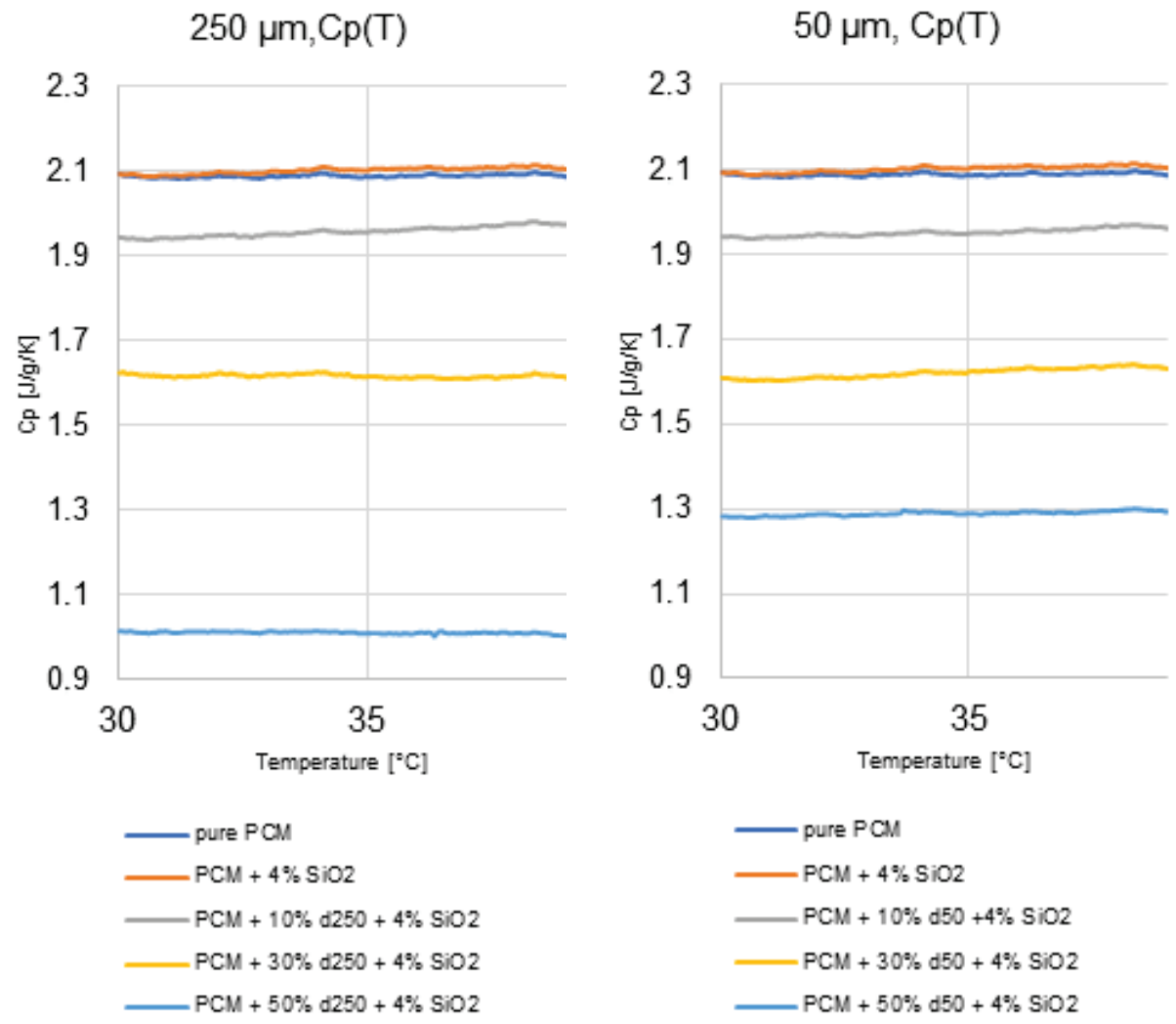

Fig. 4. Comparison of heat capacity for 10, 30, 50 mass percentages of diamond with $250 \mu \mathrm{m}$ (left) and $50 \mu \mathrm{m}$ (right) granulation with pure octadecane and octadecane with $4 \%$ of amorphous silicon dioxide

\section{Latent heat results}

Latent heat [6] was calculated by the software as an area under the heat flux vs temperature curve. Values of latent heat of all mixtures were shown on Fig. 5. Pure octadecane shown the largest and mixture with lowest amount of octadecane had the lowest. Mixture of PCM and amorphous silicon dioxide had slightly lower latent heat, because of small amount of filler. Mixtures with $10 \%$ of diamond had similar values, but lower from pure by less than $20 \%$. Mixtures with $30 \%$ of diamond slightly differed from each other but in the range of error and compared to pure PCM, they have around $30 \%$ lower latent heat. Mixtures with $50 \%$ of diamond differ significantly. Mixture with $50 \mu \mathrm{m}$ grains had less than half of pure PCM's latent heat. Mixture with $250 \mu \mathrm{m}$ had latent heat value lower by almost $70 \%$. Difference between these two mixtures may have occurred since the one with smaller grains was more homogenous. Small sample with $250 \mu \mathrm{m}$ grains was not representative for the bulk of material. As the amount of diamond increased, the standard deviation decreased because mixture became more homogenous and all samples were more similar.

Figure 6 presents a comparison of latent heat values that were measured with those that were calculated. Colours representation: white - pure PCM, orange - PCM with $\mathrm{SiO}_{2}$, blue - PCM with $50 \mu \mathrm{m}$ powder and $\mathrm{SiO}_{2}$, green - $\mathrm{PCM}$ with $250 \mu \mathrm{m}$ powder and $\mathrm{SiO}_{2}$. "Calculated latent heat" was obtained with the assumption that theoretically mixture would have latent heat equal to the percentage of latent heat of octadecane that was present in the mixture. Each of the diamondcontaining mixtures also contained $4 \%$ of mass of amorphous silicon dioxide. Analysis of the specific heat and latent heat of the relevant substances shown that, it decreased when the diamond 
was added. Higher diamond content led to a lower heat capacity, which reduced its ability to store energy. To maintain the optimal properties of PCM, its mass ratio with diamond needs to be optimized.

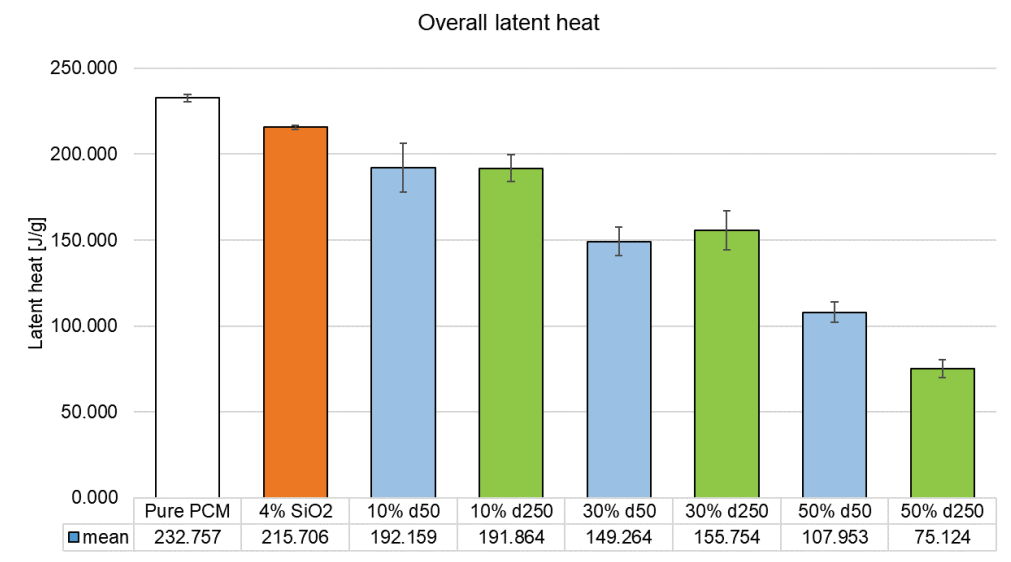

Fig. 5. Comparison of all mixtures' latent heat

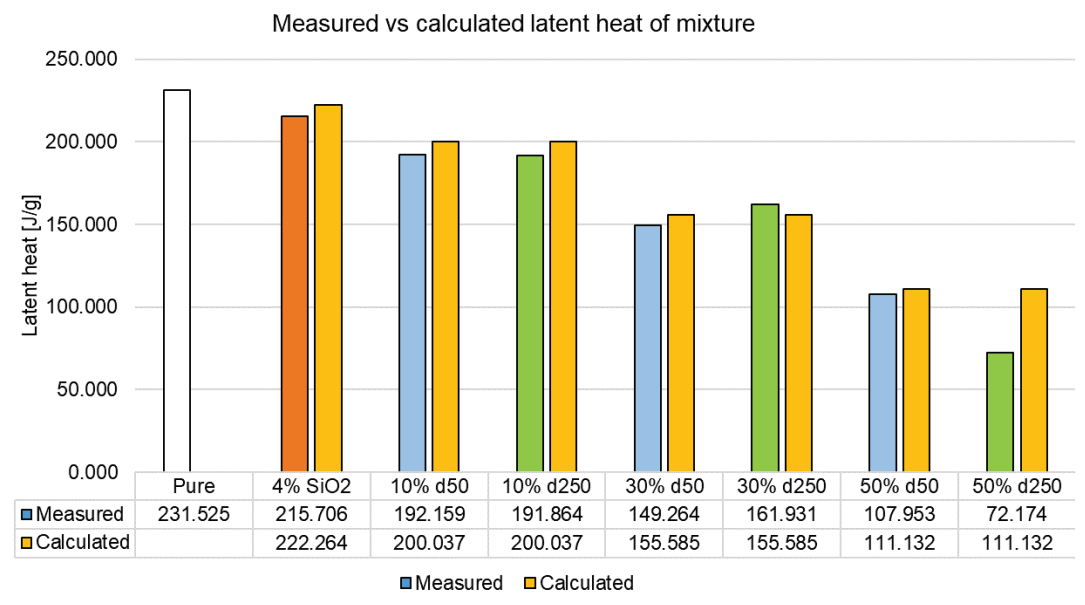

Fig. 6. Latent heat-measured vs calculated value

\section{Supercoiling effect}

Supercoiling is called the metastable state of the material in which it remains in the liquid phase below its melting point [7]. Liquids in this state exhibit significant sensitivity to external disturbances and impurities [8]. This effect was examined with use of following temperature program: initial isotherm for 3 minutes at $5^{\circ} \mathrm{C}$, heating from 5 to $40^{\circ} \mathrm{C}$, second isotherm for 3 minutes at $40^{\circ} \mathrm{C}$ and cooling from 40 to $5^{\circ} \mathrm{C}$. The analysis of acquired data showed that particles of additive acted as nucleation embryos and in result lowered degree of supercoiling. Fig. 7 shows heating/cooling process of pure octadecane while Fig. 8 shows the same process but of mixture of octadecane with $4 \%$ of $\mathrm{SiO}_{2}$. On the Fig. 9 cooling processes of three mixtures were compared PCM with $4 \%$ of $\mathrm{SiO}_{2}$ and $50 \%$ of $50 \mu \mathrm{m}$ diamond powder (solid line), PCM with $4 \%$ of $\mathrm{SiO}_{2}$ (dashed-dotted line) and pure PCM (dashed line). Peaks for mixture with less fillers were shifted more to the left - freezing point was in lower temperature. Mixtures with higher amount of fillers changed phase more dynamically. Smaller peaks for mixtures with lower amount of PCM had smaller latent heat. The shift of freezing point from 23.15 to $24.07^{\circ} \mathrm{C}$ was observed. It corresponded to change of degree of supercoiling from 3.14 to $1.85^{\circ} \mathrm{C}$. In comparison, mixture with $\mathrm{SiO}_{2}$ only and mixture with $\mathrm{SiO}_{2}$ and diamond powder combined differed very slightly although in the favour of the latter (Fig. 10). 


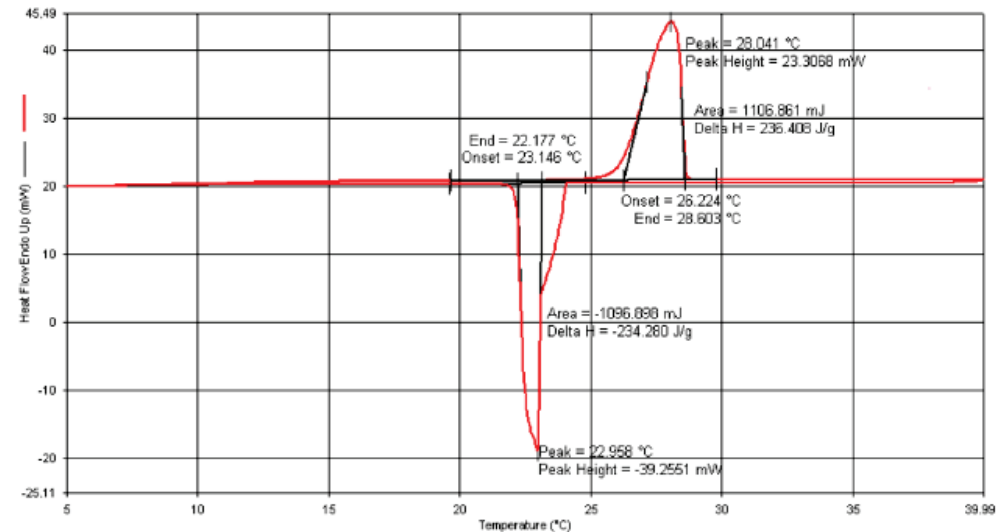

Fig. 7. Heating - cooling process for pure octadecane

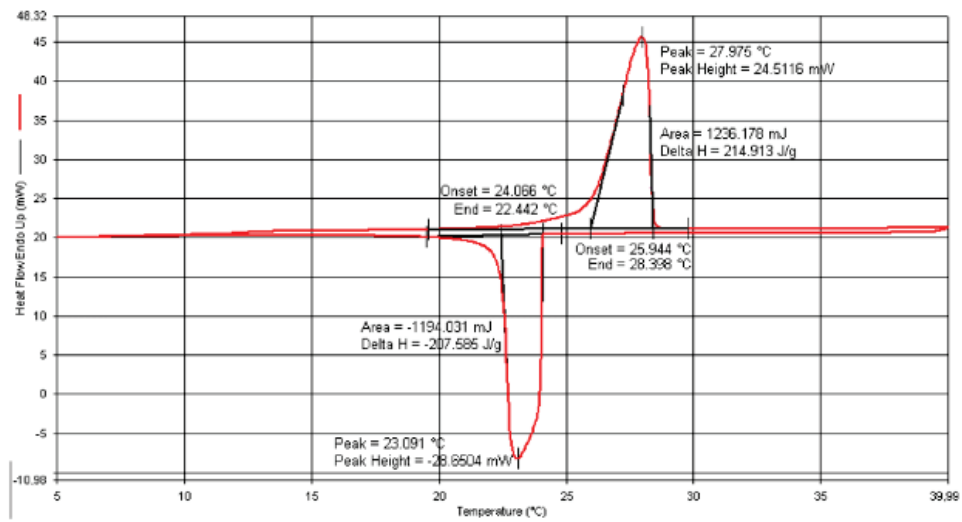

Fig. 8. Heating - cooling process of octadecane with 4\% mass percentage of amorphous silicon dioxide

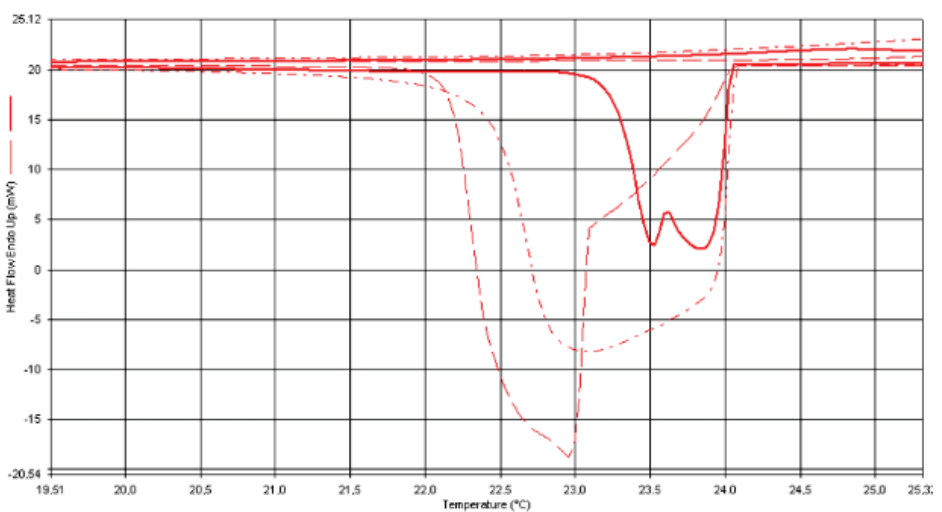

Fig. 9. Comparison of three mixtures' cooling process

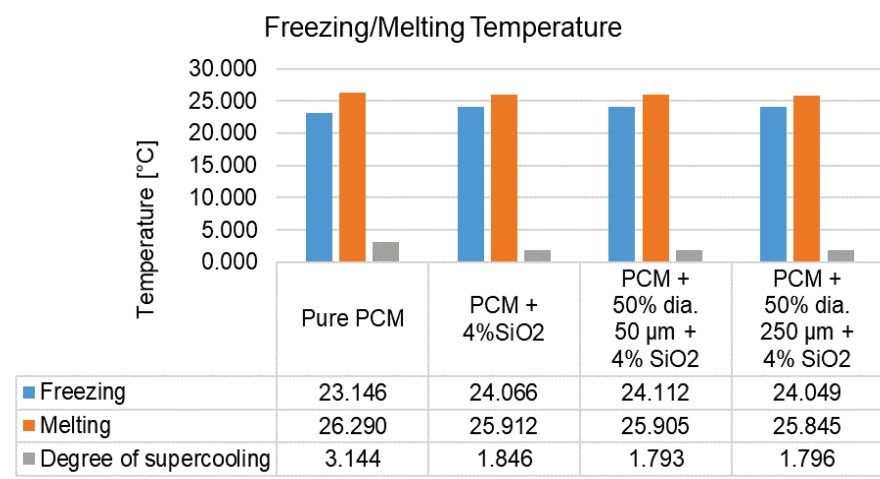

Fig. 10. Freezing/melting temperatures' comparison for different mixtures. Degree of supercoiling 


\section{Conclusions}

Application of such materials must be chosen appropriately, since it was observed that despite an increased mass fraction of amorphous silicon dioxide, especially for the bigger granulation, the stratification occurred after approximately 20 cycles of melting and solidification. The DSC test results were influenced by many factors such as ambient temperature, humidity, stabilization length of the apparatus, shape, and mass of the sample, mass of the holder and inhomogeneity of the specimens. Therefore, it was necessary to make at least three samples from each type of mixture. Examination of the specific heat of the mixtures showed that along with the growing mass content of the diamond, its value decreased even three times in comparison to pure octadecane. The particle size of the diamond also influenced the result. However, differences in the specific heat values for different granulations were insignificant. The largest difference occurred between 50 and $250 \mu \mathrm{m}$ granulation for $50 \%$ diamond mass content. The specific heat of the mixture with a mass content of $50 \%$ of diamond of $50 \mu \mathrm{m}$ particle size at a temperature of $30^{\circ} \mathrm{C}$ was about $30 \%$ larger than of a mixture with diamond of $250 \mu \mathrm{m}$ granulation. Latent heat measurements have shown that as in the case of specific heat, it decreased accordingly to the increase of diamond content in the mixture. Mixtures with $50 \%$ diamond mass content and 50 and $250 \mu \mathrm{m}$ granulation showed the lowest value of latent heat. The latent heat value for the smaller granulation was twice lower, and the larger granulation caused a decrease by almost three times. A significant difference in this value between the two granulations could occur due to inhomogeneity. Analysis of the heating and cooling of the samples showed tendency of supercoiling. The most susceptible mixture was pure octadecane since it had the least amount of nucleation embryos. The degree of supercoiling of pure PCM was approximately $3.1^{\circ} \mathrm{C}$. Mixtures of materials had a lower degree of supercoiling of about $1.8^{\circ} \mathrm{C}$. This brought to the conclusion that this method not only had an influence on specific heat and latent heat of mixtures but also improved its resistance to supercoiling. The legitimacy of using this apparatus for testing such mixtures should be considered because the sample in DSC was relatively small, which led to inhomogeneities thus the sample was not representative for the bulk of mixture. Despite thorough mixing, samples tested in the DSC were so small that the mixture was partially separated.

\section{References}

[1] Domański, R., Magazynowanie energii cieplnej, PWN, Warszawa 1990.

[2] Mehling, H., Cabeza, L. F., Heat and cold storage with PCM. An up to date introduction into basics and applications, Heidelberg: Springer Berlin Heidelberg, Berlin 2008.

[3] Nagano, K., Mochida, T., Takeda, S., Domański, R., Rebow, M., Thermal characteristics of manganese (II) nitrate hexahydrate as a phase change material for cooling systems, Applied Thermal Engineering, Vol. 23(2), pp. 229-241, 2003.

[4] Sharma, A., Tyagi, V. V., Chen, C. R., Buddhi, D., Review on thermal energy storage with phase change materials and applications - Renewable and Sustainable Energy Reviews, Renewable and Sustainable Energy Reviews, 2/2009, Vol. 13(2), pp. 318-345, 2009.

[5] Domański, R., Jaworski, M., Wiśniewski, T. S., Wymiana ciepła. Laboratorium dydaktyczne, Oficyna Wydaw. Politechniki Warszawskiej, Warszawa 2002.

[7] Castello, C., Guunther, E., Mehling, H., Hiebler, S., Cabeza, L. F., Determination of the enthalpy of PCM as a function of temperature using a heat-flux DSC - A study of different measurement procedures and their accuracy, International Journal of Energy Research, Vol. 32(13), pp. 1258-1265, 2008.

[8] Jaworski, M., Pomiary temperatury przemiany fazowej $i$ stopnia przechłodzenia materiałów stosowanych do akumulacji ciepła (PCM), Oficyna Wydaw. Politechniki Warszawskiej, Warszawa 2001.

[9] Safaria, A., Saidurb, Sulaimanb, R., Xu, Y., Donga, J., A review on supercoiling of Phase Change Materials in thermal energy storage systems, 2017.

Manuscript received 03 June 2019; approved for printing 25 September 2019 